\title{
Myeloid Differentiation Primary Response Protein Myd88
}

National Cancer Institute

\section{Source}

National Cancer Institute. Myeloid Differentiation Primary Response Protein Myd88. NCI

Thesaurus. Code C90100.

Myeloid differentiation primary response protein MyD88 (296 aa, 33 kDa) is encoded by the human MYD88 gene. This protein is involved in the modulation of signaling pathways that stimulate the innate immune response. 